\title{
Reforming International Environmental Governance: An Institutionalist Critique of the Proposal for a World Environment Organisation
}

\author{
SEBASTIAN OBERTHÜR and THOMAS GEHRING \\ Otto-Friedrich University Bamberg, Feldkirchenstr. 21, 96045 Bamberg, Germany \\ (E-mail: sebastian.oberthuer@sowi.uni-bamberg.de)
}

Accepted 2 July 2004

\begin{abstract}
This article argues that a World Environment Organisation (WEO) does not promise to enhance international environmental governance. First, we claim that the establishment of an international organisation alone in a policy field currently populated by regimes cannot be expected to significantly improve environmental governance because there is no qualitative difference between these two forms of governance institutions. Second, we submit that significant improvement of international environmental governance through institutional rearrangement must rely on a modification of decision-making procedures and/or a change of institutional boundaries. Third, we develop three principal models of a possible WEO. A WEO formally providing an umbrella for existing regimes without modifying issue-areas and decisionmaking procedures would be largely irrelevant. A WEO integrating decision-making processes of existing regimes so as to form comprehensive 'world environment rounds' of intergovernmental bargaining would be largely dysfunctional and prone to a host of negative side-effects. A 'supranational' WEO including large-scale use of majority decision-making and far-reaching enforcement mechanisms across a range of environmental issues might considerably enhance international environmental governance, but it appears to be grossly utopian. In conclusion, a WEO cannot be at the same time realistic, significant and beneficial for international environmental governance. Available political resources should be invested in advancing existing and emerging sectoral environmental regimes rather than in establishing a WEO.
\end{abstract}

Key words: co-operation theory, global governance, international environmental governance, international institutions, multilateral environmental agreements, regime theory, World Environment Organisation

Abbreviations: EU - European Union; GATT - General Agreement on Tariffs and Trade; GMEF - Global Ministerial Environment Forum; ILO - International Labour Organization; UNECE - United Nations Economic Commission for Europe; UNEP - United Nations Environment Programme; WEO - World Environment Organisation; WTO - World Trade Organization

\section{Introduction}

A World Environment Organisation (WEO) has been proposed by analysts and policy-makers alike to remedy existing problems of international environmental 
governance. Despite significant progress in the past decades, sustainable development has not been realised. International environmental problems such as the loss of biological diversity, climate change or the dispersion of persistent hazardous chemicals remain largely unresolved (UNEP 2002). The creation of a full-fledged international organisation is expected to strengthen international environmental governance, as did the establishment of the World Trade Organization (WTO) for the liberalisation of international trade (Runge 2001; Charnovitz 2002). A WEO could provide a common roof for a number of existing multilateral environmental agreements and form a new 'gravity centre' of international environmental policymaking (Esty 1994; Biermann 2000; Esty and Ivanova 2001, 2002; WBGU 2001; Whalley and Zissimos 2001; for an overview and further references see Biermann 2002, p. 298). The proposal for a WEO is one of several suggestions for strengthening 'Global Environmental Governance' on which this journal devoted a special issue in 2002 (Volume 4, No. 4).

Today, international environmental governance takes place predominantly within numerous independent institutional arrangements. A study conducted for the UN Conference on Environment and Development in Rio de Janeiro identified more than 125 separate international environmental regimes (Sand 1992; also Charnovitz 1996). Five additional environmental agreements have been concluded on average per year thereafter (Beisheim et al. 1999, pp. 350-351). International agreements regulate virtually all important regional or global environmental problems. While they have in many cases resulted in remarkable progress, difficulties still abound (e.g. Haas, Keohane and Levy 1993; Young 1999; Miles et al. 2001).

Proposals for the establishment of a WEO form part of a broader policy discussion on reforming the institutional framework of international environmental governance. The Global Ministerial Environment Forum (GMEF) of the UN Environment Programme (UNEP) aims at improving co-ordination between international treaties and other institutions relevant to the environment. Options reviewed by the GMEF include proposals to cluster multilateral environmental agreements, i.e. to integrate several agreements or certain of their parts (Oberthür 2002). The World Summit on Sustainable Development convened in Johannesburg in summer 2002 endorsed the efforts of the GMEF. ${ }^{1}$ Gupta (2002) provides an overview and analysis of further options that have been put forward.

The idea of a WEO is rooted in dissatisfaction with the current arrangements of international environmental governance and, more importantly, with the lack of effective environmental protection it has achieved so far. Proponents expect a WEO to help overcome in particular three major problems of international environmental politics (e.g. Biermann 2000). The cumbersome process of setting binding international standards for the protection of the environment might be facilitated by bargains across issue-areas and policy fields (Whalley and Zissimos 2001, 2002). Supervision and enforcement of the implementation of international environmental commitments might be enhanced, partly through the mobilisation of additional resources for transfer from North to South to assist developing countries (e.g. Bier- 
mann 2000; Esty and Ivanova 2002). In addition, disruption of international environmental governance caused by non-environmental institutions such as the WTO (Runge 2001; Brack 2002; Charnovitz 2002) and by tensions between different international environmental regimes might be mitigated or avoided. The Kyoto Protocol's potential for providing incentives for forestry activities that maximise carbon sequestration while compromising the objectives of the Convention on Biological Diversity (Pontecorvo 1999; Jacquemont and Caparrós 2002) provides an example of tensions between environmental regimes. Finally, a WEO is expected to collect and distribute environmental data and analyses (e.g. Biermann 2000; Esty and Ivanova 2002).

So far, the discussion on the merits of a WEO lacks conceptual foundation. Advocates of a WEO regularly fail to demonstrate why we should expect a WEO to fulfil the aforementioned functions more effectively than the existing institutional arrangements or potential other alternatives (Najam 2003). This would require a conceptual foundation enabling us to assess the governance capacity of varying international institutions.

This article is intended to provide conceptual foundation for the debate by examining the principal contribution that a WEO could make to enhancing international environmental governance from an institutionalist perspective. In particular, we employ co-operation and regime theory, which have greatly advanced our understanding of governance through international environmental institutions over the past 20 years or so (e.g. Haas, Keohane and Levy 1993; Gehring 1994; Young 1994; Victor, Raustiala and Skolnikoff 1998). We do not engage in a comprehensive review of individual proposals for establishing a WEO (for overviews see Biermann 2002, p. 298; Charnovitz 2002, pp. 324-329). Instead, we investigate, on the basis of co-operation and regime theory, ways in which a WEO might modify international environmental governance.

We make three claims. First, we argue that the establishment of an international organisation alone in a policy field currently populated by regimes cannot be expected to significantly improve environmental governance because there is no qualitative difference between these two forms of governance institutions. Organisations do not have at their disposal additional properties or instruments that are relevant for successful governance and that would not be available in international regimes (Section 2).

Second, we submit that any significant improvement of international environmental governance through institutional re-arrangement can rely on a modification of decision-making procedures and/or a change of institutional boundaries. Modification of decision-making procedures changes the ability of actors to influence outcomes. Modification of the boundaries of the issue-area governed affects opportunities to link issues and conclude mutually beneficial deals. In contrast, an institutional reform cannot be expected to help ensure an effective enforcement of international environmental commitments. Irrespective of decision-making procedures and institutional boundaries, non-cooperating states cannot be excluded from 
the benefits of international environmental governance, because it is predominantly about the protection of global or regional commons (Section 3).

Third, based upon the analysis of three principal models we argue that a WEO cannot be at the same time realistic, significant and beneficial for international environmental governance. A WEO formally providing an umbrella for existing regimes without modifying existing decision-making procedures would be largely irrelevant. A WEO integrating decision-making processes of existing regimes so as to form comprehensive 'world environment rounds' of intergovernmental bargaining would be largely dysfunctional and prone to a host of negative side-effects. A 'supranational' WEO including large-scale use of majority decision-making and farreaching enforcement mechanisms across a range of environmental issues might considerably enhance international environmental governance, but it appears to be grossly utopian. From an institutionalist perspective, the creation of a WEO may therefore result in efficiency gains at best (common use of secretariats, co-ordination of reporting). Political and financial resources available promise greater return if invested in advancing decision-making in existing environmental regimes (Section 4).

\section{The Distinction between Regimes and Organisations - Fiction rather than Reality}

The establishment of a World Environment Organisation cannot per se be expected to improve international environmental governance. Relevant proposals are in large part inspired by the fact that international environmental politics is predominantly based upon hundreds of separately established international regimes and does not possess a central organisation as do other areas such as international trade (Esty 1994; Runge 2001). However, there is no evidence supporting the claim implicit in these proposals that an organisation might per se be more powerful or better suited for successful governance than a regime (Najam 2003).

International environmental governance is already supported by international organisations and international regimes. Although the latter prevail, both forms are relevant. An international regime is generally based upon one or several international treaties and related instruments. Hence, international climate policy is made within the global climate regime based upon the UN Framework Convention on Climate Change and its Kyoto Protocol. Other regimes address such problems as the depletion of the ozone layer, transboundary trade in hazardous wastes, trade in endangered species (CITES), or the protection of regional seas such as the North East Atlantic, the Baltic or the Mediterranean seas. International organisations are commonly considered as actors (Abott and Snidal 1998) and defined by reference to their secretariats and their ability to enter into legal contracts (e.g. Keohane 1989, pp. 3-4; Young 1994, pp. 163-183; Barnett and Finnemore 1999). They also play an important role in international environmental governance. The International Maritime Organization (IMO) hosts a number of agreements for the protection of the marine environment, WHO elaborates air quality standards, FAO manages fish 
resources. Last, but not least, UNEP - despite the fact that it is not a specialised agency but only a UN programme - has promoted the elaboration of several international environmental regimes since the early 1970s.

International regimes and international organisations are in many respects very similar (Simmons and Martin 2002, p. 194) and do not significantly differ in their governance capacity. They both constitute "persistent and connected sets of rules and practices that prescribe behavioural roles, constrain activity, and shape expectations" (Levy, Young and Zürn 1995) and provide their members with the necessary forums and communication channels to elaborate collectively binding decisions in accordance with established procedures (see also Abbott and Snidal 1998, pp. 1516). They also do not differ systematically with respect to their patterns of governance. While decision-making in many international organisations remains limited by the requirements of consensus, the procedures in various international environmental regimes are surprisingly far-reaching and include delegation of decisionmaking authority (see Section 3.1).

The formal characteristics of the international organisations mentioned above are not suited for a clear-cut distinction and they do not refer to elements that matter for effective governance. While the ability to enter into an external contract under international law may be relevant for some specific tasks, it does not generally increase the governance ability of an organisation, because successful governance regularly depends on establishing co-operation between the members of an institution and thus on internal decision-making. Likewise, the success of international governance cannot be attributed to the existence of secretariats. For example, the particular strength of the WTO is usually not attributed to its secretariat but to its decision-making apparatus, in particular to its rigid and influential dispute settlement mechanism (Hoekman and Kostecki 1995, pp. 44-50; Jackson 1999, pp. 107137).

What is more, if one were to equal international organisations with secretariats, the distinction between international regimes and organisations would become completely blurred. Not only organisations but also regimes possess their own bureaucracies. Consequently, both regimes and existing organisations comprise substantive rules and obligations as well as some sort of a secretariat. The creation of a WEO would amount to the integration of the secretariat services of different existing institutions, for example UNEP and a number of international environmental agreements. Such a step could hardly be expected to significantly contribute to mitigating any of the major deficiencies of international environmental governance.

International organisations do not generally govern broader issue-areas than international regimes, and they are not more successful. Many established international organisations, such as WTO, the Food and Agriculture Organization of the UN (FAO), WHO or the ILO govern large issue-areas. However, others are more specialised, such as the World Customs Organization (WCO) that administers customs codes used in international trade. In contrast, some international regimes such 
as the regime on climate change and the 1982 United Nations Convention on the Law of the Sea (UNCLOS) manage an enormous scope of inter-connected issues without establishing a formal organisation. At the same time, effective organisations such as the WTO contrast with less successful ones such as the ILO and with a number of remarkably successful international environmental regimes (e.g. Haas, Keohane and Levy 1993; Victor, Rustiala and Skolnikoff 1998; Young 1999; Miles et al. 2001).

The transformation of an international regime into an organisation may largely amount to an act of symbolic policy-making because it does not per se increase governance capacity (see also Charnovitz 2002, p. 337). The mere fact that the original General Agreement on Tariffs and Trade (GATT), which had evolved over almost 50 years, was converted into the WTO in 1994 did not significantly enhance the governance capacity of the institution. Likewise, environmental governance would not significantly change if the regime for the protection of the global climate or the regime for the protection of the Baltic Sea (Helsinki Commission) were transformed into small international organisations. Hence, labelling an existing international regime (agreement) as an organisation is largely a symbolic act. We do not want to claim that symbolic politics is irrelevant (Edelman 1967). States may have good reasons to take symbolic action such as the transformation of the Conference for Security and Cooperation in Europe into the Organization for Security and Cooperation in Europe without enhancing the authority of the institution after the end of the cold war to symbolise the new security situation in Europe. From the perspective of co-operation theory, however, symbolic action cannot be expected to systematically enhance the governance capacity of a given institution.

\section{The Decision-Making Capacity of International Institutions}

An institutional reform will only be relevant for the effectiveness of international environmental governance, if it significantly affects the decision-making capacity of international institutions. In this section, we argue that this factor may be influenced by the design of decision-making processes (Section 3.1) and by the delimitation of the areas governed (Section 3.2).

\subsection{The Design of Decision-Making Processes}

International governance institutions constitute decision-making apparatuses that produce collectively binding decisions and supervise their implementation. Active governance intended to change undesired behaviour and improve sub-optimal outcomes requires collective decision-making (see also Keohane 1993; Gehring 2002). As a group, the actors choose how they individually ought to behave in order to bring about a desired co-operative outcome. Hence, collective decision-making constitutes the core of active governance. All international institutions encompass 
their own decision-making processes (see Levy, Young and Zürn 1995) that enable their members to adapt and develop these institutions dynamically (Gehring 1994).

Simple ad hoc negotiations are the least demanding mechanism for the making of collective decisions under the 'anarchic' conditions of the international system. This mechanism is frequently resorted to by states in international relations. It allows governments individually to pursue their own distributive interests based on their bargaining power, and collectively to mould norms. It is generally assumed that the distribution of the benefits of an arrangement emerging from a bargaining process will largely reflect the power constellation existing outside the negotiations (Elster 1989, pp. 50-96).

Co-ordination by intergovernmental negotiations is, however, subject to several limitations. First, negotiations are frequently slow and cumbersome. Even if all participants intend to reach agreement, they must distribute co-operation gains and will compete for the biggest possible 'piece of the cake' (Lax and Sebenius 1986). Second, the ability to co-ordinate by means of simple negotiations decreases with the complexity of the negotiating agenda. If a negotiation addresses many interconnected issues, participants will face increasing difficulties in assessing concessions and proposed deals. These difficulties will be exacerbated, if the issues under negotiation are marked by scientific uncertainty that characterises many environmental issues. As a consequence, transaction costs of negotiations and the likelihood of failure increase. Third, the dynamic change inherent in many economic, technological and environmental policy areas requires that agreements be flexibly adapted to changing circumstances, which may be difficult to attain in ad hoc negotiations. Fourth, rational actors can be interested in establishing particularly credible commitments binding their partners and themselves by effective dispute resolution and sanctioning mechanisms, which can hardly be provided for in simple negotiations.

The limitations inherent in co-ordination by simple negotiations provide incentives for rational actors to devise more ambitious institutional arrangements. They may do so in at least three ways. First, participating actors may postpone some of the issues to be dealt with to later negotiating rounds in order to reduce complexity or to enhance the adaptability of the institution. They may enter into "incomplete contracts" (Williamson 1985), which regulate only the most pertinent aspects of an issue and postpone everything else to later decisions. For example, parties to the Montreal Protocol of 1987 agreed to periodically review and further develop the phase-out schedule of ozone-depleting substances such as chlorofluorocarbons (CFCs). And the United Nations Framework Convention on Climate Change was intended to provide an institutionalised forum for subsequent negotiations on emission reduction obligations. Actors thus tend to create enduring negotiating processes. Later negotiating rounds inescapably take place within an institutionalised context, which influences the preferences of the participants and makes the development of the institution path-dependent (Young 1994; Pierson 1996). If a considerable number of similar decisions with a limited scope are to be taken over time, general criteria may evolve that guide these decisions, limit the room for 
manoeuvre in the negotiations and further a transition to an exchange of reasonable arguments (Risse 2000) instead of pure bargaining based on power.

Second, actors may create specialised decision-making processes (e.g. scientific assessments, non-compliance procedures, or simple negotiating sub-groups) that focus on some aspects of the entire decision load and free them from doing everything at the same time within the same process. In this case, the overall package is elaborated within a number of parallel or consecutive negotiation processes with a limited scope that fulfil complementary functions and establish a division of labour. The resulting specialisation within country delegations frequently promotes agreement, because it supports recourse to accepted expert knowledge and encourages the emergence of "epistemic communities" (Haas 1992). Even if, as is frequently the case, the sub-agreement forms part of the overall negotiation package that needs to be adopted by consensus ("nothing is agreed until everything is agreed"), the relevance of procedural rules increases and the ability of the participants to resort to their bargaining power outside the negotiations is limited. For example, the scientific, technological and economic assessment panels established within the framework of the Montreal Protocol proved to have a significant influence on the negotiations on the phase out of ozone-depleting substances, although they constituted merely advisory bodies with no formal decision-making powers (Parson 2003). Likewise, international climate negotiations regularly proceed in a number of separate contact groups addressing different items of the negotiating agenda. Specialisation of negotiation processes facilitates a transition from interest-based bargaining to an exchange of reasoned arguments (arguing).

Finally, actors may forgive their veto power that would otherwise enable them to block unacceptable decisions by subjecting themselves to majority decision-making or to decisions by committees with limited membership. Delegation of decisionmaking authority will be possible even under the conditions of the current international system, if the individual decisions are linked so closely that they can only be accepted or rejected in their entirety and a "selective exit" (Weiler 1991, p. 2412) is excluded. 'Horizontal' decision-making based upon the consensus of all participating actors can be supplemented by a 'vertical' component, provided that the overall package creates a net benefit for all participants.

The decision-making procedures of several international environmental regimes are surprisingly far-reaching and include delegation of decision-making authority. Member states of the regime for the protection of the ozone layer may adopt binding adjustments of emission reduction commitments by a qualified majority, and an Executive Committee composed of seven developing countries and seven industrialised countries decides on the allocation of financial resources for the phase-out of ozone depleting substances in the South (DeSombre and Kauffman 1996). In the International Whaling Commission and in the international regime on trade in endangered species, decisions on catch quota and the listing of endangered species respectively are taken by majority, as are far-reaching decisions in other environmental regimes (Churchill and Ulfstein 2000, pp. 638-641). In an increasing number 
of international environmental regimes, separate procedures and committees have also been established to identify and address cases of non-compliance. The compliance committee under the Kyoto Protocol even is to decide on significant sanctions (Churchill and Ulfstein 2000, pp. 643-647; Ehrmann 2000; Oberthür and Marr 2002).

While differentiation of negotiation processes increases the autonomy of the institution vis-à-vis its member states and reduces their ability to control decisions, it enhances the decision-making capacity of an international institution. Rational actors will trade off the gains from more flexible decision-making against the (partial) loss of control over the content of institutionally produced decisions (Koremenos, Lipson and Snidal 2001). In simple ad hoc negotiations, the participants constitute the only source of influence on results. If decisions are taken within an established institution, they will be influenced by prior decisions. If they are made in a network of specialised negotiating groups, they may be affected by expert considerations. If collectively binding decisions are taken by a majority or specialised committees with limited membership, they will not require consent by all member states and may not even require consent by any member.

Decision-making arrangements may be improved within existing international environmental agreements without founding a World Environment Organisation. Existing arrangements are tailor-made for addressing particular governance problems and reflect the willingness of their members to trade off influence against an increased overall decision-making capacity. International environmental regimes develop over time and their arrangements can be adapted to new needs. While there is room for further improvement, progress is frequently precluded by the resistance of some member states based on parochial interests. It is difficult to see how a WEO could systematically contribute to overcoming this resistance.

\subsection{The Delimitation of Problem Areas}

The issue-areas governed by international institutions are not externally given, they are socially constructed by the participants in the process of their interaction (Haas 1975). International negotiations cannot address all co-operation problems pending between states simultaneously, because the multitude of issues would be impossible to handle. Governments can negotiate about almost anything, but not about everything at the same time in the framework of a single negotiating round. Therefore, they identify certain problems to be dealt with in, and exclude others from, a particular negotiating round. The issue-areas governed by international institutions are always "artificially" delimited. Their boundaries are contingent, i.e. they could have been drawn differently. In bilateral negotiations, the participants can enhance the scope for co-operation by enlarging the issue-area and creating package deals that are composed of partial deals with an asymmetric distribution of benefits (Tollison and Willet 1979). In multilateral negotiations, a deliberate expansion of the 
agenda is more difficult to achieve, because the number of bilateral relations and of unintended side-effects to be taken into account increase exponentially with the number of participating actors. As a result, the delimitation of multilateral issueareas usually develops around a substantive core and is frequently subject to protracted pre-negotiations (Gross Stein 1989).

The delimitation of an issue-area has far-reaching consequences for the ensuing negotiation process. Adding or subtracting issues (and parties) will change the constellation of interests within the negotiation process and determine the potential for co-operation (Sebenius 1983). The delimitation of an issue-area establishes effective limits for the attention of the participants (Scharpf 1991) so that actors jointly accept the partition of reality in order to limit the complexity of the respective negotiating agenda. As long as the negotiating partners accept it, an actor does not have an incentive to depart from the definition unilaterally, even if he would have preferred different boundaries. Accordingly, the participating actors will define their preferences in the negotiations with regard to the issues under consideration therein, while all other issues are difficult to introduce and may therefore be ignored for the time being.

Actors participating in negotiations are faced with the challenge to collectively optimise the delimitation of an issue-area so as to enhance the opportunities for successful co-operation and the prospect of achieving a mutually accepted outcome. An optimal delimitation of an issue-area will avoid two pathologies. A very narrow definition promises a manageable scope of negotiations, but involves the risk of providing too little potential for co-operation and trade-offs (Whalley and Zissimos 2001, 2002). In contrast, a very broad definition will provide ample room for linkages and trade-offs between actors, but creates the risk that the negotiating partners are overwhelmed by the complexity of too many problems. The suitable scope of an issue-area depends upon the particularities of the issues at stake.

Some issue-areas are comparatively broadly defined in order to facilitate the emergence of numerous small-scale co-operation projects which might not have been born, or which would not survive, separately. The International Labour Organization (ILO), for example, has helped adopt several hundred conventions defining minimum social and labour standards (de la Cruz, Potobsky and Swepston 1996) for which states might not have gathered and attended separate conferences and established independent supervisory mechanisms. The same is true for the World Health Organization which addresses a broad range of issues. In these cases, transaction costs may be assumed to be high as compared to co-operation gains.

In other cases, broad-range international institutions have increased the prospects of beneficial trade-offs. International trade, for example, is based on the systematic exploitation of comparative advantages. A country will specialise in the production and export of those products in which it is competitive, whereas it will import those products which it cannot produce competitively. Despite some intra-industry trade, liberalising just trade in cars would not lend itself to international co-operation because producers and exporters of cars would benefit from this step, but not the 
importing countries. The integration of different product markets creates significantly more room for mutually beneficial co-operation. The same is true for the linkage of trade in goods (GATT) with trade in services (GATS) and the protection of intellectual property (TRIPs). Hence, international trade is regulated by a single international institution, namely WTO (Hoekman and Kostecki 1995), and not by a set of separate product regimes.

The striking institutional fragmentation of international environmental politics reflects the high political salience of environmental issues and their particular problem structure. Unlike trade policy, environmental co-operation projects do not require integration because most international and global environmental issues address the protection of common goods and encompass a prisoners' dilemma constellation of interests. They can be regulated in separate co-operative arrangements that ensure mutual benefits for the members. For example, all members of the international ozone regime or the regime on biological diversity benefit from an enhanced protection of the ozone layer and an improved conservation of nature (in the case of developing countries partially ensured by side-payments).

Unlike international health and labour protection policies, environmental cooperation projects are usually sufficiently important to be institutionalised separately from existing institutions. Transaction costs involved in achieving co-operation are reduced by a number of existing international organisations or semi-independent organisational structures. Existing organisations such as UNEP (protection of the ozone layer, transboundary movements of hazardous wastes), the United Nations Economic Commission for Europe (UNECE; long-range transboundary air pollution in Europe), the UN General Assembly (climate change), and IMO (pollution from ships) have supported the emergence of most international environmental regimes. Compared to the huge investments and far-reaching changes of administrative procedures required to implement international environmental commitments, transaction costs related to the maintenance of separate institutions are small. Hence, even international environmental regimes created within the framework of international organisations such as those mentioned above regularly gain institutional autonomy from their parent institutions (Churchill and Ulfstein 2000).

The institutional fragmentation of international environmental governance indicates a strength rather than a weakness of environmental co-operation. While the delimitation of issue-areas governed by international institutions is subject to design efforts by the actors involved, it is not entirely incidental. In general, issue-areas are to ensure mutual benefits for the participants in order to enable effective governance. A wrong delimitation of an issue-area can render co-operation impossible. The multitude of well-functioning environmental institutions indicates that actors have, for the most part, succeeded in defining viable issue-areas in international environmental governance and that an integration of issue-areas is not required in order to ensure mutual benefits of the parties involved. In Section 4.2, we will turn in more detail to the question of whether an integration of issue-areas may nevertheless have the potential of enhancing international environmental governance. 


\section{Options for a World Environment Organisation: Three Models}

The idea of a more encompassing WEO is closely related to the integration of environmental issue-areas. Neither the mere transformation of individual regimes into single-issue organisations nor the re-design of their decision-making procedures correspond to the idea of a WEO and are thus considered here. The organisation is generally expected to form the institutional core of international environmental governance. Consequently, it would have to provide the home for a number of international environmental regimes such as the regimes on global climate change, for the protection of the ozone layer and for the preservation of biodiversity.

In this section, we develop three basic models for a future WEO. While an almost unlimited number of options exist, the specific design of a WEO will follow one of these models (for similar distinctions see Biermann 2000, 2001; WBGU 2001). The models differ with respect to the two parameters discussed in the preceding section, namely the decision-making processes and the delimitation of the issue-area(s) governed. Actors could create a formal umbrella organisation without changing issue-areas and decision-making procedures of existing regimes substantively (Section 4.1). They could also integrate existing issue-areas more substantively without introducing significantly different decision-making procedures (Section 4.2). Finally, they could both integrate issue-areas and fundamentally re-organise decision-making therein (Section 4.3).

\subsection{UN Model: An Umbrella Organisation}

States could establish a World Environment Organisation limited to providing a formal umbrella for existing sector-specific environmental regimes. It would leave substantively untouched the current institutional structure of international environmental governance. The established boundaries of the issue-areas governed by international regimes and their existing decision-making procedures would remain unchanged. The organisation could stimulate international environmental co-operation by lowering the threshold of regime building and reduce transaction costs, e.g. by offering constant secretariat services, or fulfilling certain auxiliary functions. Many proposals for establishing a WEO (Biermann 2000; Esty and Ivanova 2002) emphasise these aspects, that are also a major focus of proposals for 'clustering' multilateral environmental agreements (Oberthür 2002). A WEO designed in this way would follow the model of the United Nations which also provides a comparatively loose umbrella for a number of rather independent regulatory activities in separate issue-areas such as human rights or the law of the sea (Mingst and Karns 2000; White 2002).

A WEO following the UN model would not significantly affect the governance capacity of institutions making international environmental policy. The currently separate environmental issue-areas would not be integrated, because the sectorspecific decision-making processes would remain in place. The participating actors 
would continue to determine their preferences in relation to those issues falling inside the respective issue-areas, while ignoring other issues. Opportunities for co-operation would continue to arise exclusively as a result of these sector-specific preferences. If decision-making proceeded separately for each issue-area, although within the framework of an umbrella organisation, negotiators would not receive additional incentives to co-ordinate their sector-specific activities and to look for possible issuelinkages or for package deals cutting across the boundaries of established issueareas. Those negotiating climate change would continue to focus on measures to stabilise the global climate, while members of the regime on biological diversity would continue to concentrate on preserving biodiversity. Whereas an exchange of information may be facilitated, resulting tensions between both regimes regarding forestry activities (maximisation of carbon sequestration versus conservation of biological diversity) would persist. Likewise, the mechanisms for supervising and facilitating implementation such as non-compliance procedures and other functional bodies would not significantly change, because they would remain sectorally organised.

A WEO constructed after the UN model could be expected to realise limited efficiency gains at best, but it would not make a significant contribution to the solution of problems of international environmental governance related to decisionmaking, implementation and co-ordination. A certain potential for combining certain auxiliary functions of environmental regimes (e.g., reporting, review of implementation) might exist, but gains would be moderate (Oberthür 2002). The bigger problems of international environmental governance could not be solved because this WEO would not significantly change the delimitation of existing issueareas or the design of the related decision-making processes. The creation of an umbrella organisation would thus largely be a matter of symbolic politics.

\subsection{WTO Model: Creating Comprehensive World Environment Rounds}

Alternatively, a WEO could systematically integrate issue-areas so far governed by separate international environmental regimes without abandoning the familiar intergovernmental structure. Issue-areas will be integrated, if the specific decisionmaking processes of existing and future international environmental regimes, in particular their annual or biennial conferences of the parties, are merged into more encompassing negotiating rounds. International environmental policy would then be developed in recurring 'global environmental rounds'. This design follows the approach of the WTO, because the regulation of world trade is developed in comprehensive world trade rounds (Hoekman and Kostecki 1995, pp. 12-20).

In contrast to the UN model, such a WEO would have a substantial impact on international environmental governance. Members would determine their preferences related to a broader negotiating agenda taking into account additional options for package deals and trade-offs. They might also more easily detect, and might attempt to avoid, negative side-effects of a given regulation on other policies pursued 
within the same institution. However, these potentially positive effects on international environmental governance contrast with important drawbacks.

The increased potential for issue-linkage resulting from the integration of issueareas is unlikely to help advance international environmental governance. Whalley and Zissimos (2001, 2002) rightly insist that increased opportunities for issue-linkages and side-payments facilitate agreement in international negotiations. However, issue-linkage will only be helpful, if asymmetries in the distribution of costs and benefits are complementary across issues so that different actors benefit (most) from co-operation on different subjects and all actors equally benefit from the overall package. Unfortunately, complementary interests, which characterise trade negotiations, do not systematically exist across different issue-areas in international environmental policy. For example, it is unlikely that difficulties in the international co-operation to combat climate change would be more easily overcome, if negotiations were combined with those on ozone depletion, biodiversity or other regimes. Complementarity of interests does not exist because the United States is currently the laggard in many, if not most, global environmental issues (Paarlberg 1999). The US can hardly be expected to accept stringent controls on greenhouse gas emissions in order to ensure an effective protection of, for example, the ozone layer and cooperation on persistent organic pollutants. If this situation gave way to a complementarity of interests, it would be incidental and temporary and could not be expected to provide a firm foundation for long-term co-operation.

Benefits from an integration of issue-areas are limited because international environmental governance is predominantly about the preservation of collective goods rather than club goods. Free international trade has the properties of a club good that is accessible only to the members of the club (Cornes and Sandler 1999). States are effectively excluded from reaping the benefits of a liberalised world trade unless they open their own markets (Hoekman and Kostecki 1995, pp. 27-30). In contrast, environmental protection is frequently a collective good. It will be difficult to prevent a state from taking a free ride if it cannot be excluded from enjoying the collective good of environmental protection. Countries refusing to co-operate to protect the ozone layer cannot be excluded from the benefits of a stabilised ozone layer. Accordingly, states have an incentive to stay out of costly co-operation (Olson 1965) that will increase with every issue that a country opposes. Thus, a WEO following the WTO model threatens to undermine its own basis and endangers gains so far realised through sector-specific co-operation in international regimes.

Likewise, issue-linkage through integration of issue-areas does not help pressure non-co-operating states and enforce implementation of international environmental commitments. Proponents of environmental protection cannot credibly threaten to make protection of the ozone layer conditional on US acceptance of controls on greenhouse gases, because realising this threat would harm themselves at least as much as the opponent. The same logic applies to the enforcement of obligations. While disregard of obligations within WTO may be effectively prosecuted by excluding non-complying countries from benefits in any suitable area of interna- 
tional trade, this threat is usually not available in environmental institutions: A country's non-compliance with obligations to conserve biological diversity cannot usefully be responded to by not complying with commitments to protect the ozone layer.

Modest additional opportunities for issue-linkages and side-payments contrast with a significantly enhanced complexity of negotiations, which makes it more difficult to reach agreement. If states had unlimited information processing capacity, they would best deal with all problems pending among them at the same time. In reality, complexity creates significant impediments for decision-making and reaching agreement, because more issues are to be dealt with in a single negotiation process. Experience from available precedents suggests that complexity is a factor that seriously limits effective decision-making and significantly slows down the process. The Uruguay Round of trade negotiations took some 8 years (1986-1994: Hoekman and Kostecki 1995, pp. 19-20), while the negotiations at the Third UN Conference on the Law of the Sea lasted even for 9 years (1973-1982; Sebenius 1984).

In several respects, a WTO-like WEO does not change the status quo at all. It is unlikely that it is apt to mobilise the additional financial resources needed to reinforce the capacity of developing countries to implement international obligations and develop effective environmental policies. There is no indication that industrialised countries might be more willing to provide additional financial resources to assist implementation of international environmental commitments in developing countries if issue-areas were integrated. Why should they be prepared to do so only because the ozone regime has, for example, been merged with the climate change regime and become part of a larger institutional complex? It should also be noted that the Global Environment Facility (GEF) has already been established as an overarching institution providing financial assistance supporting the implementation of several international environmental agreements (Oberthür 2002, pp. 324-325).

A WTO-like WEO is also unlikely to help resolve the co-ordination problems existing between environmental and economic institutions such as the WTO (Brack 2002). Several proposals for a WEO are focusing on the interface between economic and environmental governance (e.g. Runge 2001). However, it is difficult to see how a larger environmental organisation could ensure that agreements between WTO members do not undercut environmental regulation. The difference in power between the WTO and international environmental governance will continue irrespective of the existence of a WEO because the WTO can grant and withdraw trade advantages, while any environmental institution supplying a collective good cannot exclude individual actors from benefiting (see above). Where particular opportunities for enforcement exist, they can be used without establishing a WEO. Side-payments and technical assistance can be withdrawn, with the significant drawback that such action only affects the poorer members and diminishes their willingness to cooperate. More importantly, several multilateral environmental agreements, including the Montreal Protocol for the protection of the ozone layer and the 1973 Convention on International Trade in Endangered Species of Wild Fauna and Flora (CITES), 
allow for authorising or imposing specific trade sanctions in response to non-compliance (Charnovitz 1996). Pressure on the WTO (and other economic institutions) will largely depend on the determination of the members of these regimes to effectively implement such sanctions. It seems that the WTO, through the jurisdiction of its Dispute Settlement Body, increasingly accepts appropriately designed environmental trade sanctions (Charnovitz 1998), so that, in practice, trade sanctions (and other enforcement options) can already be employed by the parties to environmental regimes. It is difficult to see how the establishment of a WEO could add significant new opportunities in this respect.

Finally, a WTO-like WEO could make a difference for co-ordination problems between the environmental institutions integrated into the WEO, but the benefits to be reaped would remain very limited. A WEO would facilitate exchange of information and co-ordination across environmental issue-areas contributing to a better integration of approaches. However, recent research suggests that tensions between environmental institutions are relatively rare and have been handled relatively successfully within the current fragmented system of environmental institutions (Oberthür and Gehring 2003). The benefits to be realised from a better integration of environmental issue-areas are therefore moderate at best.

Altogether, it is highly questionable whether the benefits that may be reaped in this area justify the costs and dangers of increased complexity and unproductive issue linkage. While a WEO following the WTO model would significantly change environmental policy-making, it does not promise significant progress towards the resolution of the major problems of international environmental governance. To the contrary, it is likely to be dysfunctional, because it creates disincentives rather than incentives for accepting additional environmental commitments and threatens to overwhelm negotiators with an undesirable complexity of issues that would retard action.

\subsection{EU Model: Delegating Extensive Competencies to a WeO}

To avoid the negative consequences of the WTO model, a WEO could both integrate the issue-areas of existing environmental regimes and systematically reorganise the related decision-making processes. It would then be shaped after the European Union (EU). The EU constitutes a single encompassing institution governing an extensive area comprising numerous policies. In principle, it thus provides extensive opportunities for linking issues and facilitating co-operation by side-payments. Nevertheless, decision-making is not overwhelmed by an overly complex agenda of issues because opportunities for linkage are severely limited in practice. Despite grand bargains on the European Treaties (Moravcsik 1998), there are no comprehensive negotiation rounds. Instead, decisions are largely delegated to subsidiary decision-making processes, supranational organs (European Commission, European Court of Justice) and independent bodies or agencies (Majone 1997). Each of these processes is specialised on some issues, so that complexity is reduced. Their decision- 
making capacity is enhanced because they regularly employ majority decisionmaking, and in many cases member states do not play the dominant role any more. Moreover, decisions are not part of large packages to be agreed upon at the end, but enter into force separately. In order to avoid that states only adhere to agreements that are to their liking, the option of "selective exit" (Weiler 1991) is firmly closed, and member states must either accept all commitments of the institution or sacrifice their membership.

A WEO following the EU model would promise to make a substantial contribution to resolving the main problems of international environmental governance (Pollack 2003). First, majority voting and delegation of decision-making authority would reduce the decision-making problems notorious in international institutions. It would not only prevent individual actors from blocking decisions, but produce decisions that are less influenced by the parochial interests of individual states. Second, the institutional design would require, and thus allow, that member states establish powerful supervisory and enforcement mechanisms, because the institution would comprise numerous decisions with asymmetrical distributional effects that would not have gained the support by all members concerned. Otherwise, effective implementation of commitments could not be ensured. Third, a 'supranational' WEO would allow for the establishment of overarching criteria and collision rules to be followed in the subordinated specialised decision-making processes in order to resolve co-ordination problems and potential conflicts such as that between the Kyoto Protocol and the Convention on Biological Diversity.

Even the governance capacity of a WEO designed according to the EU model would have notable limits. The attractiveness and power of the EU stem primarily from the advantages offered by the single market as opposed to the prospect of participating in European environmental governance. The same is true for the North American Free Trade Agreement (NAFTA) and the accompanying North American Agreement on Environmental Cooperation (NAAEC) and its Commission for Environmental Cooperation (Runge 2001). A similar link to other policy fields would presumably not be part of a newly established WEO, because it would transform the concept of a World Environment Organisation into something much broader. A WEO integrating only environmental issue-areas could not be expected to resolve the enforcement problems encountered with respect to collective environmental goods referred to in Section 4.2. Even the most stringent supervisory and enforcement mechanism could not prevent non-compliant countries from taking a free ride on members by leaving the organisation or ignoring its rules. The notable strength of EU enforcement of environmental regulation is in particular due to the linkage with other policies such as single market policy and agricultural and regional policies, rather than the particular design of environmental policy making. For the same reason, such a WEO could not be expected to mitigate tensions with economic institutions such as the WTO.

Finally, even the most powerful 'supranational' WEO is unlikely to raise substantial additional financial resources. There is no reason to assume that the 
integration of issue-areas and the reorganisation of decision-making processes would increase the preparedness of member states to provide additional contributions. Paying EU member states have not been willing to agree to and maintain a massive transfer of financial resources in the framework of the EU Structural Funds and the EU Common Agricultural Policy because of the desirability of the goals pursued thereby, but because of the substantial benefits they reap from European integration in other areas (e.g., single market, monetary union). Similar trade-offs beyond the field of the environment are not in sight for a WEO.

Most important, a 'supranational' WEO relying on the EU model cannot be expected to be realised in the foreseeable future, because this would require the transfer of far-reaching competencies to an international organisation. Supranationalism has been confined to the EU so far where it depends on a comparatively high degree of political, economic and social coherence in a single region of the world. We cannot see any indication that a significant number of states from different regions would be prepared to consider ceding sovereignty to an international institution to the extent required.

\section{Conclusion}

The establishment of a World Environment Organisation does not promise to enhance international environmental governance. Currently, this governance occurs through hundreds of separate international regimes and is characterised by a high degree of institutional fragmentation. Proponents of a WEO aim at integrating existing regimes into a more centralised institution in order to improve decisionmaking, implementation and co-ordination in international environmental governance. However, they have largely failed to answer the fundamental question of how and why governance within the framework of an organisation would be superior to the status quo. From an institutionalist perspective, proposals for establishing a WEO lack promise because such an institution cannot at the same time be realistic, significant and beneficial for international environmental governance.

Any institutional reform can significantly affect international environmental governance only if it succeeds in modifying the design of the decision-making processes applied in international environmental institutions and the scope of the issue-areas covered by these institutions. International institutions consist of systems of rules and norms that are established and developed by their members in order to govern distinct issue-areas. The design of their decision-making procedures and the scope of their issue-areas are important determinants of their governance capacity. Replacing the consensus principle currently prevailing in international relations at least partially with majority voting and delegation of decision-making authority to limited-membership bodies and independent agencies could substantially enhance the ability to arrive at decisions in international institutions. An issue-area's ideal scope will be reached if it allows for sufficient trade-offs between issues so as to ensure net benefits for all major 
actors, while preventing negotiations from becoming over-complex and unmanageable. From an institutionalist perspective, any significant effect of an institutional reform of international environmental governance will be based on modifications either of decision-making processes or of boundaries of issue-areas or of both. Such institutional reform can help strengthen environmental interests but it cannot substitute for a lack of political interest in and support for environmental protection.

The establishment of an organisation as such does not promise to significantly improve international environmental governance. International organisations possessing legal personality and bureaucracies do not a priori possess a higher governance capacity than international regimes, which are based upon one or several international treaties short of possessing legal personality. Neither are international organisations throughout characterised by particularly far-reaching decision-making procedures, nor is the construction of the issue-areas governed necessarily superior to international regimes. Both organisations and regimes delegate decision-making authority and employ majority decision-making to varying extents, with sophisticated decision-making within international environmental regimes reaching far beyond arrangements found in many international organisations. Both of them can govern smaller or larger problem areas depending on whether the respective area allows for the emergence of international co-operation. Finally, there are both examples of more and less effective international organisations and international regimes, and many environmental regimes appear to be particularly successful.

Depending on its design, a newly established WEO could either constitute symbolic action, or create a host of negative side-effects, or be unrealistic. A WEO designed according to the UN model would assemble the existing environmental regimes under a common roof without affecting the scope of their issue-areas or their decision-making procedures. Creating this umbrella organisation would be a symbolic act that would have little or no effects on governance. In contrast, a WEO following the WTO model would profoundly change decision-making by systematically integrating existing environmental issue-areas and leading to comprehensive "world environment rounds". As a consequence, however, the complexity of negotiation rounds would increase, while opponents of parts of the comprehensive package would face incentives to stay outside the institution or ignore part of its regulations. A WEO relying upon the EU model could be expected to successfully avoid the complexity trap. Members would be requested to accept majority decisionmaking and delegation of decision-making authority and would be faced with the choice of either accepting all or none of the decisions taken within the WEO. While this WEO would have some prospect of contributing to solving the problems of international environmental governance, it would require a far-reaching transfer of competencies from nation states to the organisation. Since such a transfer is currently widely unacceptable for states in the international system, an EU-like WEO can be considered grossly utopian.

The effectiveness of any WEO, however designed, would remain limited by the particular problem structure prevailing in international environmental governance. 
A WEO would hardly be able to prevent countries from taking a free ride on faithful members by staying outside the organisation or ignoring their obligations. It also cannot be expected per se to enhance the preparedness of member states to provide increased financial funds for environmental protection. There are ample opportunities for improving the current institutional arrangements of international environmental governance. Efforts to enhance the effectiveness of new and emerging sectoral environmental regimes may be complemented by endeavours aiming at improved efficiency and coherence by integrating secretariat services and meetings of parties and strengthening the catalytic and facilitative role of UNEP short of establishing a WEO. From an institutionalist perspective, environmental protection will be better served if the political resources available are invested in achieving progress in the development of the existing institutional arrangements.

\section{Acknowledgements}

We gratefully acknowledge the helpful comments of two anonymous reviewers. The contents of the article remain solely in the responsibility of the authors.

\section{Note}

1. Paragraph 140 (d) of the Johannesburg Plan of Implementation (available at $<\mathrm{http}: / /$ www.un.org/esa/sustdev/documents/WSSD_POI_PD/English/POIToc.htm>).

\section{References}

Abbott, K. W. and D. Snidal (1998), 'Why States Act through Formal International Organizations', Journal of Conflict Resolution 42(1), 3-32.

Barnett, M. N. and M. Finnemore (1999), 'The Politics, Power, and Pathologies of International Organizations', International Organization 53(4), 699-732.

Beisheim, M., S. Dreher, G. Walter, B. Zangl and M. Zürn (1999), Im Zeitalter der Globalisierung? Thesen und Daten zur gesellschaftlichen und politischen Denationalisierung. BadenBaden: Nomos.

Biermann, F. (2000), 'The Case for a World Environment Organization', Environment 42(9), 22-31.

Biermann, F. (2001), 'The Emerging Debate on the Need for a World Environment Organization: A Commentary', Global Environmental Politics 1(1), 45-55.

Biermann, F. (2002), 'Strengthening Green Global Governance in a Disparate World Society: Would a World Environment Organisation Benefit the South?', International Environmental Agreements: Politics, Law and Economics 2(4), 297-315.

Brack, D. (2002), 'Environmental Treaties and Trade: Multilateral Environmental Agreements and the Multilateral Trading System', in G. P. Sampson and W. Bradney Chambers, eds., Trade, Environment, and the Millennium, 2nd edn. (pp. 321-352) Tokyo: UN University Press.

Charnovitz, S. (1996), 'Trade Measures and the Design of International Regimes', Journal of Environment and Development 5(2), 168-196. 
Charnovitz, S. (1998), 'The World Trade Organization and the Environment', Yearbook of International Environmental Law 8, 98-116.

Charnovitz, S. (2002), 'A World Environment Organization', Columbia Journal of Environmental Law 27(2), 321-357.

Churchill, R. R. and G. Ulfstein (2000), 'Autonomous Institutional Arrangements in Multilateral Environmental Agreements: A Little-Noticed Phenomenon in International Law', The American Journal of International Law 94, 623-659.

Cornes, R. and T. Sandler (1999), The Theory of Externalities, Public Goods and Club Goods, 2nd edn Cambridge: Cambridge UP.

de la Cruz, H. B., G. Potobsky and L. Swepston (1996), The International Labor Organization. The International Standards System and Basic Human Rights. Boulder, CO: Westview Press.

DeSombre, E. R. and J. Kauffman (1996), 'The Montreal Protocol Multilateral Fund: Partial Success Story', in R. O. Keohane and M. A. Levy, eds., Institutions for Environmental Aid: Pitfalls and Promise (pp. 89-126). Cambridge, MA: MIT Press.

Edelman, M. (1967), The Symbolic Uses of Politics. Urbana, Chicago, London: University of Illinois Press.

Ehrmann, M. (2000), Erfüllungskontrolle im Umweltvölkerrecht - Verfahren der Erfüllungskontrolle in der umweltvölkerrechtlichen Vertragspraxis. Baden-Baden: Nomos.

Elster, J. (1989), The Cement of Society. A Study of Social Order. Cambridge: Cambridge UP.

Esty, D. C. (1994), Greening the GATT. Trade, Environment and the Future. Washington, DC: Institute for International Economics.

Esty, D. C. and M. Ivanova (2001): Making International Environmental Agreements Work: The Case for a Global Environmental Organization, Yale Center for Environmental Law and Policy Working Paper Series, Working Paper 2/1. New Haven, May 2001.

Esty, D. C. and M. Ivanova (2002), 'Revitalizing Global Environmental Governance: A Function Driven Approach', in D. C. Esty and M. Ivanova, eds., Global Environmental Governance: Options and Opportunities (pp. 181-204). New Haven, CT: Yale School of Forestry and Environmental Studies.

Gehring, T. (1994), Dynamic International Regimes: Institutions for International Environmental Governance. Frankfurt/Main: Peter Lang.

Gehring, T. (2002), Die Europäische Union als komplexe internationale Organisation. Wie durch Kommunikation und Entscheidung soziale Ordnung entsteht. Baden-Baden: Nomos.

Gross Stein, J. (1989), 'Getting to the Table: The Triggers, Stages, Functions, and Consequences of Pre-negotiation', in J. Gross Stein, ed., Getting to the Table: The Processes of International Pre-negotiation (pp. 239-268). Baltimore: Johns Hopkins UP.

Gupta, J. (2002), 'Global Sustainable Development Governance: Institutional Challenges from a Theoretical Perspective', International Environmental Agreements: Politics, Law and Economics 2(4), 361-388.

Haas, E. B. (1975), 'Is There a Hole in the Whole? Knowledge, Technology, Interdependence, and the Construction of International Regimes', International Organization 29(3), 827876.

Haas, P. M. (1992), 'Banning Chlorofluorocarbons: Epistemic Community Efforts to Protect Stratospheric Ozone', International Organization 46(1), 187-224.

Haas, P. M., R. O. Keohane and M. A. Levy (eds.) (1993), Institutions for the Earth. Sources of Effective International Environmental Protection. Cambridge, MA.: MIT Press.

Hoekman, B. M. and M. M. Kostecki (1995), The Political Economy of the World Trading System. From GATT to WTO. Oxford: Oxford UP.

Jackson, J. H. (1999), The World Trading System. Law and Policy of International Economic Relations, 2nd edn Cambridge, MA: MIT Press. 
Jacquemont, F. and A. Caparrós (2002), 'The Convention on Biological Diversity and the Climate Change Convention 10 Years After Rio: Towards a Synergy of the Two Regimes?', Review of European Community and International Environmental Law 11(2), 139180.

Keohane, R. O. (1989), International Institutions and State Power. Essays in International Relations Theory. Boulder, CO: Westview Press.

Keohane, R. O. (1993), 'The Analysis of International Regimes: Towards a EuropeanAmerican Research Programme', in V. Rittberger, ed., Regime Theory and International Relations, Oxford: Clarendon Press.

Koremenos, B., C. Lipson and D. Snidal (2001), 'The Rational Design of International Institutions', International Organization 55(4), 761-799.

Lax, D. A. and J. K. Sebenius (1986), The Manager as Negotiator. Bargaining for Cooperation and Competitive Gain. New York, NY: Free Press.

Levy, M. A., O. R. Young and M. Zürn (1995), 'The Study of International Regimes', European Journal of International Relations 1, 267-330.

Majone, G. (1997), 'The New European Agencies. Regulation by Information', Journal of European Public Policy 4(2), 262-275.

Miles, E. L., A. Underdal, S. Andresen, K. Lee, J. B. Skjærseth and J. Wettestad (2001), Explaining Regime Effectiveness: Confronting Theory with Evidence. Cambridge, MA: MIT Press.

Mingst, K. A. and M. P. Karns (2000), United Nations in the Post-Cold War Era. Boulder, CO: Westview.

Moravcsik, A. (1998), The Choice for Europe. Social Purpose and State Power from Messina to Maastricht. Ithaca, NY: Cornell University Press.

Najam, A. (2003), 'The Case against a New International Environmental Organization', Global Governance 9(3), 367-384.

Oberthür, S. (2002), 'Clustering of Multilateral Environmental Agreements: Potentials and Limitations', International Environmental Agreements: Politics, Law and Economics 2(4), $317-340$

Oberthür, S. and S. Marr (2002), 'Das System der Erfüllungskontrolle des Kyoto-Protokolls: Ein Schritt zur wirksamen Durchsetzung im Umweltvölkerrecht', Zeitschrift für Umweltrecht 13(2), 81-89.

Oberthür, S. and T. Gehring (2003), 'Institutional Interaction: Toward a Systematic Analysis', 2003 International Studies Association Annual Convention, Portland, 26 February - 1 March 2003.

Olson, M. (1965), The Logic of Collective Action. Public Goods and the Theory of Groups. Cambridge, MA: Harvard UP.

Paarlberg, R. L. (1999), 'Lapsed Leadership: U.S. International Environmental Policy Since Rio', in N. J. Vig and R. S. Axelrod, eds., The Global Environment: Institutions, Law, and Policy (pp. 236-255). Washington, DC: Congressional Quarterly Press.

Parson, E. A. (2003), Protecting the Ozone Layer: Science, Strategy, and Negotiation in the Shaping of a Global Environmental Regime. Oxford: Oxford University Press.

Pierson, P. (1996), 'The Path to European Integration. A Historical Institutionalist Analysis', Comparative Political Studies 29(2), 123-163.

Pollack, M. (2003), The Engines of European Integration. Delegation, Agency, and Agenda Setting in the EU. Oxford: Oxford UP.

Pontecorvo, C. M. (1999), 'Interdependence between Global Environmental Regimes: The Kyoto Protocol on Climate Change and Forest Protection', Zeitschrift für ausländisches öffentliches Recht und Völkerrecht 59(3), 709-749.

Risse, T. (2000), 'Let's Argue!' Communicative Action in World Politics', International Organization 54(1), 1-39. 
Runge, C. F. (2001), 'A Global Environment Organization (GEO) and the World Trading System', Journal of World Trade 35(4), 399-426.

Sand, P. H. (ed.) (1992), The Effectiveness of International Environmental Agreements. A Survey of Existing Legal Instruments. Cambridge: Cambridge UP.

Scharpf, F. W. (1991), 'Games Real Actors Could Play. The Challenge of Complexity', Journal of Theoretical Politics 3(3), 277-304.

Sebenius, J. K. (1983), 'Negotiation Arithmetics: Adding and Subtracting Issues and Parties', International Organization 37(2), 281-316.

Sebenius, J. K. (1984), Negotiating the Law of the Sea. Cambridge, MA: Harvard UP.

Simmons, B. A. and L. L. Martin (2002), 'International Organizations and Institutions', in W. Carlsnaes, T. Risse and B. A. Simmons, eds., Handbook of International Relations (pp. 192211). London: Sage.

Tollison, R. D. and T. D. Willett (1979), 'An Economic Theory of Mutually Advantageous Issue Linkages in International Negotiations', International Organization 33(4), 425-449.

Victor, D. G., K. Raustiala and E. B. Skolnikoff (eds.) (1998), The Implementation and Effectiveness of International Environmental Commitments: Theory and Practice. Cambridge, MA, and London: MIT Press.

UNEP (2002), Global Environment Outlook 3. London: Earthscan.

WBGU (German Advisory Council on Global Change) (2001), World in Transition: New Structures for Global Environmental Policy, London: Earthscan.

Weiler, J. H. H. (1991), 'The Transformation of Europe', Yale Law Journal 100(8), 2403-2483.

Whalley, J. and B. Zissimos (2001), 'What Could a World Environmental Organization Do?', Global Environmental Politics 1(1), 29-44.

Whalley, J. and B. Zissimos (2002), 'Making Environmental Deals: The Economic Case for a World Environment Organization', in D. C. Esty and M. Ivanova, eds., Global Environmental Governance: Options and Opportunities (pp. 163-180). New Haven, CT: Yale School of Forestry and Environmental Studies.

White, N. D. (2002), The United Nations System. Toward International Justice. Boulder, London: Lynne Rienner.

Williamson, O. E. (1985), The Economic Institutions of Capitalism. Firms, Markets, Relational Contracting. New York: Free Press.

Young, O. R. (1994), International Governance. Protecting the Environment in a Stateless Society. Ithaca: Cornell UP.

Young, O. R. (ed.) (1999), The Effectiveness of International Environmental Regimes: Causal Connections and Behavioural Mechanisms. Cambridge, MA.: MIT Press. 